\title{
SIDS: parental awareness and infant care practices in contrasting socioeconomic areas in Cardiff
}

\author{
A Shrivastava, P Davis, D P Davies
}

Cardiff Community

Health Care Trust,

Lansdowne Hospital,

Cardiff

A Shrivastava

Department of Child Health, University of Wales College of Medicine, Cardiff P Davis

D P Davies

Correspondence to: Dr A Shrivastava,

Department of Paediatrics, Southend Hospital,

Prittlewell Chase,

Southend-on-Sea SS0 ORY.

Accepted 18 March 1997

Table 1 Data on parental awareness and infant care practices of mothers in two different socioeconomic areas; results are number (\%) except for social class

\begin{tabular}{llll}
\hline & Deprived area & Affluent area & $\chi^{2}$ test \\
\hline Mothers & $81(55)$ & $67(45)$ & \\
Social class 3-5 (\%) & 91 & 30 & \\
Mothers' awareness & & & \\
$\quad$ Cot death awareness & $76(94)$ & $66(98)$ & $\mathrm{NS}$ \\
$\quad$ Sleeping position: back/side & $70(86)$ & $62(92)$ & $\mathrm{NS}$ \\
No smoking & $57(73)$ & $48(72)$ & $\mathrm{NS}$ \\
Avoiding overheating & $69(85)$ & $50(75)$ & $\mathrm{NS}$ \\
$\quad$ Summoning medical help & $6(7)$ & $2(3)$ & $\mathrm{NS}$ \\
Mothers' practice & & & \\
Sleeping position & $18(22)$ & $33(49)$ & $\mathrm{p}<0.003$ \\
$\quad$ Back & $42(52)$ & $20(30)$ & $\mathrm{p}<0.02$ \\
$\quad$ Side & $21(26)$ & $14(21)$ & $\mathrm{NS}$ \\
$\quad$ Back or side & $80(99)$ & $60(90)$ & $\mathrm{NS}$ \\
Sleeping with parents & $10(12)$ & $10(15)$ & $\mathrm{NS}$ \\
$\quad$ In parents' room & & & \\
$\quad$ In parents' bed & $34(42)$ & $10(15)$ & $\mathrm{p}<0.002$ \\
Smoking & $42(52)$ & $13(19)$ & $\mathrm{p}<0.001$ \\
$\quad$ During pregnancy & & & \\
$\quad$ At home & $13(16)$ & $9(13)$ & $\mathrm{NS}$ \\
Overheating & $71(88)$ & $57(85)$ & $\mathrm{NS}$ \\
$\quad$ > 3 blankets/duvets/quilts used & $30(37)$ & $23(34)$ & $\mathrm{NS}$ \\
$\quad$ Room heating comfortable & $65(80)$ & $57(85)$ & $\mathrm{NS}$ \\
$\quad$ Knows room temperature & $30(37)$ & $40(60)$ & $\mathrm{p}<0.02$ \\
Summoning medical help & & & \\
Breast feeding & & & \\
& & &
\end{tabular}
socioeconomic factors

Sudden infant death syndrome (SIDS) remains a major cause of postneonatal mortality, accounting for $29 \%$ of postneonatal deaths in Wales. ${ }^{1}$ Recent studies, in particular the recent Confidential Enquiry into Stillbirths and Deaths in Infancy, ${ }^{2}$ have highlighted the link between SIDS and socioeconomic deprivation, and particularly the link with smoking. Reducing the residuum of deaths from SIDS is a particular challenge and will probably require new strategies. This study aims to guide the delivery of prevention strategies by comparing mothers' awareness of SIDS and their current infant care practices on reducing the risk between two contrasting socioeconomic areas of Cardiff.

\section{Methods}

Abstract den infant death syndrome (SIDS) and infant care practices were compared in an area of relative deprivation and one of relative affluence in Cardiff. Awareness was high in both areas. More infants slept on the side in the deprived area $(p<0.02)$. One in three babies was exposed to cigarette smoking, significantly more in the deprived area $(p<0.001)$. Health professionals should discourage side sleeping and smoking, especially in areas of deprivation.

(Arch Dis Child 1997;77:52-53)

Keywords: SIDS; awareness; parenting practices;

Two district wards in the area of deprivation were matched with four district wards in the more affluent area. These areas were chosen from 1991 census data to give an approximately equal birth rate. Mothers of all babies born in these areas between January 1996 and March 1996 were asked to participate in the study. Health visiting for both areas was derived from the same team, with common training and policies. Each mother was interviewed by her own health visitor at the first routine postnatal visit following a standard questionnaire. The questionnaire included both data on the mother's awareness of SIDS and the advice on the reduction of the SIDS rate, and also questions on infant care practices. Socioeconomic status of individual families studied was determined by occupation of either parent. Data were analysed using $\chi^{2}$ tests (table 1).

\section{Results}

One hundred and forty eight questionnaires were completed, 81 from the more disadvantaged area (91\% in social classes 3-5) and 67 from the more affluent area $(30 \%$ in social classes 3-5). No parent refused to be interviewed.

Awareness of SIDS and of the risk reducing measures was high in both areas, apart from the advice on seeking medical help for symptoms and signs of illness (in the leaflet circulated by the Foundation for the Study of Infant Deaths this point is phrased 'If you think your baby is unwell contact your doctor'). This piece of advice was only mentioned by eight mothers.

There were important differences in infant care practices. Mothers from the more deprived area were more likely to lay the baby on its side $(\mathrm{p}<0.02)$ and mothers in the more affluent area were more likely to lay the baby on its back $(p<0.003)$. Only two infants were lain to sleep prone, and both of these were from the more affluent area. Infants in the more deprived area were more likely to be exposed to cigarette smoke, both during and after pregnancy $(p<0.001)$. Twenty two infants $(15 \%)$ were lain to sleep with more than the recommended amount of bedding, that is, more than three blankets or a duvet or quilt, though this did not vary between the two areas under study. The majority of infants (140) slept in the parents' room, and 17 infants $(12 \%)$ slept in the parents' bed at night. Breast feeding was more prevalent in the more affluent area $(\mathrm{p}<0.02)$. 


\section{Discussion}

Mothers were almost universally aware of SIDS, and the vast majority were also aware of current advice on simple measures to reduce the risk. Recent observational studies have focused on the risks of sleeping babies on their sides $^{3}$ and of parental smoking. ${ }^{4}$ The fact that $42 \%$ of mothers in our study slept their babies on their sides while only one third slept their babies exclusively on their backs suggests that this advice needs to be reaffirmed.

Thirty per cent of mothers smoked during pregnancy and $37 \%$ of infants were exposed to smoke after birth. Smoking was much more common in the deprived area. Mothers are therefore reluctant to change their cigarette smoking habits despite their awareness that this is a risk factor for SIDS. ${ }^{4}$ The observation that $15 \%$ of infants are still lain to sleep with excessive bedding indicates that this piece of advice should also be re-emphasised. ${ }^{5}$

That $14 \%$ of infants slept with their parents in the parental bed (co-sleeping) is interesting but difficult to interpret, given that the families were interviewed only once when the infant was around 10 days old. In this district eight of the last 23 infants dying of SIDS had been co-sleeping with their parents at the time. It is possible that co-sleeping is a risk factor for SIDS $^{6}$ and local advice to parents is to keep the baby in a cot adjacent to the parent bed, avoiding co-sleeping, especially if the parents smoke or drink alcohol. Parents are advised to pay particular attention that the bedding is not too warm when the infant is in their bed. This advice is contained in the local parent held record.
CONCLUSION

The variation in SIDS rates between the more deprived and more affluent areas of Cardiff is not adequately explained by a lack of awareness of the 'reduce the risk' factors. Future health promotion strategies might more usefully be focused on avoiding the practice of laying babies to sleep on their sides and more specifically on practical measures to reduce smoking, especially in the areas of deprivation. It has also to be appreciated that the association of SIDS with parental smoking may not be causal. The social variables that are closely correlated with smoking and SIDS must also be determined in seeking to reduce the risk of SIDS even further.

We thank all the mothers for their cooperation and the health visitors for enthusiastically filling in the questionnaires.

1 Cartlidge PHT, Stewart JH, Hopkins JM. All Wales perinatal survey and confidential enquiry into stillbirths and deaths in infancy. Annual Report, 1995.

2 National Advisory Body for CESDI. Annual report, 1994. London: Department of Health, 1996.

3 Fleming PJ, Blair PS, Bacon C, et al. Environment of infants during sleep and risk of the sudden infant death syndrome: results of 1993-5 case-control study for confidential inquiry into stillbirths and deaths in infancy. BMF inquiry into still

1996;313:191-5.
4 Blair PS, Fleming PJ, Bensley D, et al. Smoking and the sudden infant death syndrome: results of 1993-5 casecontrol study for confidential inquiry into stillbirths and deaths in infancy. BMF 1996;313:195-8.

5 Gilbert RE, Rudd PT, Berry PJ, et al. Combined effect of infection and heavy wrapping on the risk of sudden unexpected infant death. Arch Dis Child 1992;67:171-7.

6 Mitchell EA. Co-sleeping and sudden infant death syndrome. Lancet 1996;348:1466. 